\title{
EDITORIAL
}

\section{Putting pen to paper during a pandemic: increased manuscript submissions to the JNS Publishing Group}

\author{
Douglas Kondziolka, MD, FRCSC, ${ }^{1}$ William T. Couldwell, MD, $\mathrm{PhD},{ }^{2}$ and \\ James T. Rutka, MD, PhD, FRCSC ${ }^{3}$ \\ ${ }^{1}$ Associate Editor, Journal of Neurosurgery Publishing Group; ${ }^{2}$ Editor-in-Chief, Neurosurgical Focus; and ${ }^{3}$ Editor-in-Chief, \\ Journal of Neurosurgery Publishing Group, Charlottesville, Virginia
}

A s the COVID-19 pandemic took hold of virtually all societies around the world, necessitating stringent lockdown measures as a means of preventing catastrophic spread of the virus, the Journal of Neurosurgery quickly published a collection of editorials on the impact of COVID-19 on the practice of neurosurgery (https://thejns.org/collection/covid19). In keeping with best practices in business, all members of the journal editorial office in Charlottesville began a "work from home" schedule on March 15, 2020. This could be facilitated seamlessly given that all journal office departments, from peer review to production, were set up with online connectivity to ensure that the requisite daily work could be completed without delays.

In February 2020, we began to see a rise in manuscript submissions to the journal as compared to preceding years. At first it was almost imperceptible, but in the ensuing weeks it became quite clear that we were being challenged with a very significant number of new submissions across all print journals (Fig. 1). From February to June 2020, the Journal of Neurosurgery received 576 more manuscripts than those during the same 4 months in 2019; the Journal of Neurosurgery: Spine received 345 more manuscripts; and the Journal of Neurosurgery: Pediatrics received 170 more manuscripts. All told, for these 4 months, there were 1091 more new manuscript submissions to the print journals than had been seen in 2019 (Fig. 2). A similar increase in manuscript submissions was also found for the topic-based issues of Neurosurgical Focus.

Interestingly, such a sudden rise in manuscript submissions has been noted in academic publishing in the fields of science and healthcare. At the recent European Association of Science Editors Virtual Conference held on June 12, 2020, the conference theme was Editors and Editing in Times of Crisis (https://ease.org.uk/ease-events/virtual- conference-2020/). Some journals had noted a near 5-fold increase in manuscript submissions during the months of the pandemic. ${ }^{1}$ This has required several scientific journals to provide appropriate wording to authors to alert them of potential delays in the peer-review process. In our journal office, there are two full-time staff in the Peer Review Department for the print journals, Samantha Geouge and Rhonda Jeffers. They are responsible for processing all new submissions, ensuring that the manuscripts are formatted according to journal style, and providing correspondence to all authors. Needless to say, they have felt the heavy weight of these new manuscript submissions the most (Fig. 3).

Once these new manuscript submissions have passed the journal formatting requirements, the associate editor and editors in chief review each paper to determine which manuscripts should be sent out for peer review. During the peak of the pandemic, our workload increased considerably as we read, triaged, and assigned for peer review more than 175 manuscripts per week. Prior to the pandemic, our typical volume of new manuscript submissions was approximately 90 per week. So, in effect, we handled twice the volume of new manuscript submissions during the COVID-19 period.

Why this episodic increase in manuscript submissions? As has been pointed out in numerous articles in the journal's COVID-19 collection, neurosurgeons were unable to perform a good portion of their routine clinical duties. During the lockdown, most neurosurgical services were reduced to caring for patients with emergency conditions, such as ruptured aneurysms, traumatic brain injury, brain tumors, and hydrocephalus. Patients with non-urgent neurosurgical conditions, such as degenerative spine disease, epilepsy, movement disorders, and unruptured arteriovenous malformations or aneurysms, were unable for the 


\section{February to June 2020}

576

more

manuscripts

submitted to

\section{Journal of Neurosurgery}

$+55 \%$ compared to 2019

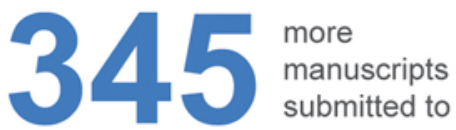

Journal of Neurosurgery: Spine

$+77 \%$ compared to 2019

$11 \begin{aligned} & \text { more } \\ & \text { manuscripts } \\ & \text { submitted to }\end{aligned}$

\section{Journal of Neurosurgery: Peds}

$+78 \%$ compared to 2019

FIG. 1. Numbers of manuscripts submitted to each of the print journals of the JNSPG from February to June 2020 with comparisons to the same timeframe for 2019. In total, 1091 more new manuscripts were received and processed for these 4 months in 2020 versus 2019. Figure is available in color online only.

most part to receive treatment. It is tempting to speculate that neurosurgeons who were unable to carry out their usual clinical duties were motivated to write new papers on their research, complete papers that had been started, or redirect papers to the journal if they had not been accepted elsewhere. On the whole, we are inspired by the notion that neurosurgeons would use the time provided by

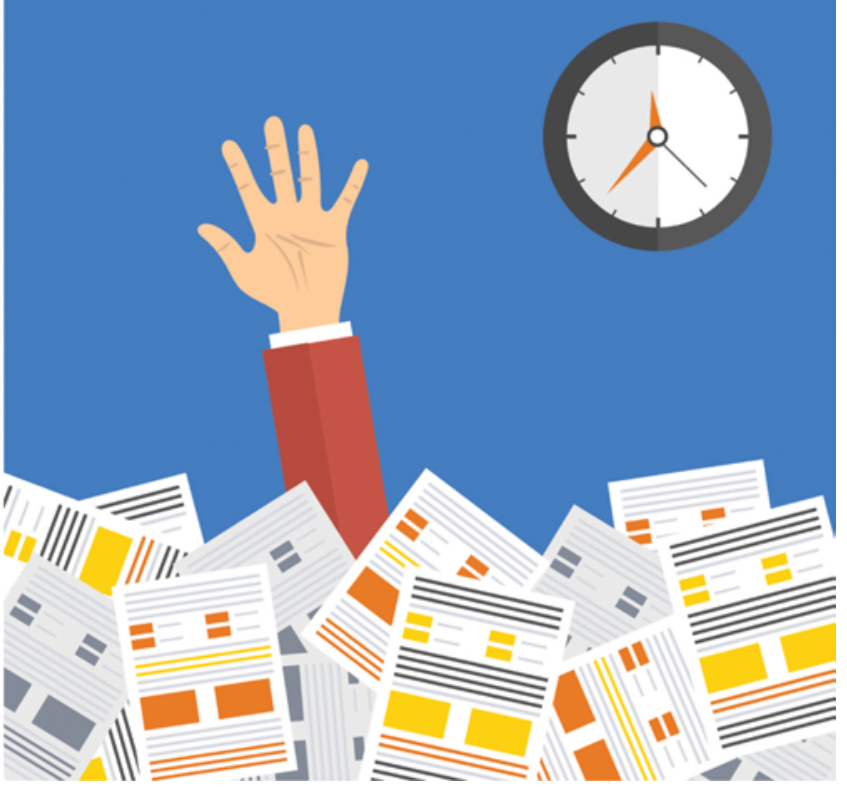

FIG. 3. With more than 1000 more new submissions for the first 6 months of 2020 as compared to the number in 2019, it is easy to understand how the Peer Review Department, the editors in chief, the associate editor, and members of the editorial board could be overwhelmed by the sheer number of new manuscript submissions. Figure is available in color online only.

the pandemic to work diligently on these academic projects.

While many of these new submissions were excellent and worthy of undergoing peer review, we confide that some were not. We could tell quite readily that some of the manuscripts submitted to the journal had been reviewed elsewhere and that these authors had rather quickly decided to send these studies to the journal without due attention to our formatting requirements. As mentioned in a previous editorial, with well over 5000 manuscripts submitted to the journal annually, we are able to publish a

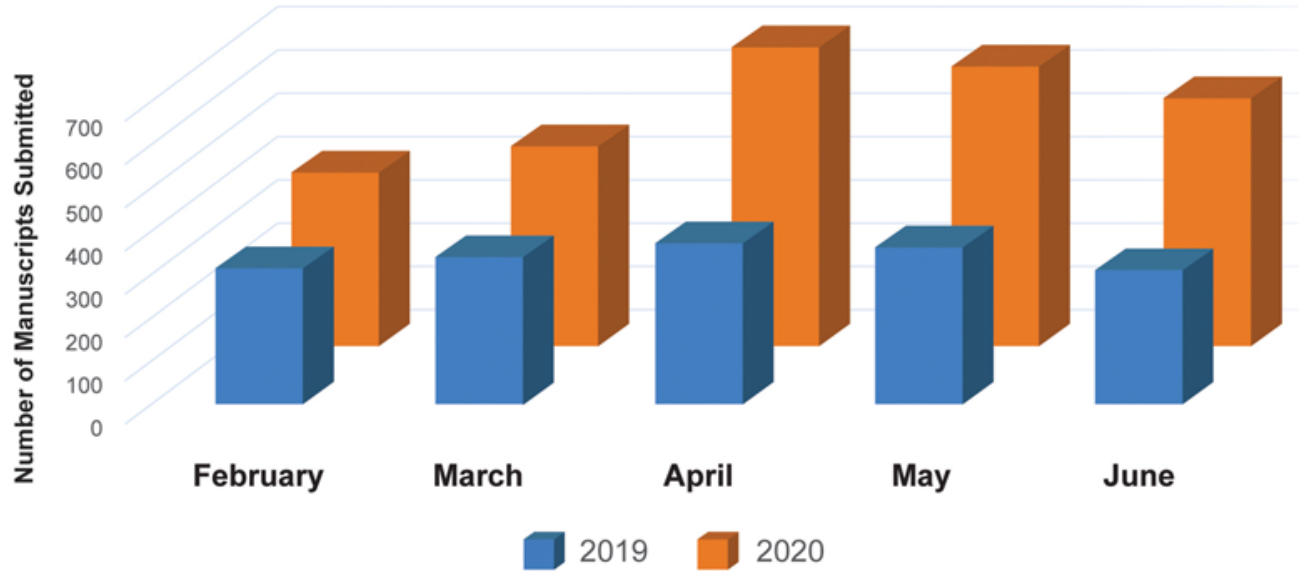

FIG. 2. Bar graph depicting the differences between manuscripts received in 2019 and 2020 for all print journals combined. The number of new manuscript submissions peaked in April and has shown evidence of some decline since. Figure is available in color online only. 
TABLE 1. New editorial board members, the JNS Publishing Group 2020-2021

\begin{tabular}{llll}
\hline \multicolumn{1}{c}{ Name } & \multicolumn{1}{c}{ Institution } & \multicolumn{1}{c}{ Area of Expertise } & Print Journal \\
\hline Manish Aghi & University of California, San Francisco & Brain tumors, neuroendoscopy, brain mapping & JNS \\
\hline Andrew Carlson & University of New Mexico & $\begin{array}{c}\text { Vascular/endovascular, neurocritical care, skull } \\
\text { base }\end{array}$ & JNS \\
\hline Elizabeth Claus & Yale University & Brain tumors, epidemiology, databases & JNS \\
\hline Kai-Ming Fu & Weill Cornell Medicine & Deformity, minimally invasive spine, oncology & JNS: Spine \\
\hline Gerald Grant & Stanford University & Brain tumors, epilepsy, traumatic brain injury & JNS: Peds \\
\hline Stephanie Greene & University of Pittsburgh & Vascular, spinal dysraphism, hydrocephalus & JNS: Peds \\
\hline Christoph Hofstetter & University of Washington & Spinal cord injury, minimally invasive spine & JNS: Spine \\
\hline Mark Krieger & University of Southern California & Brain tumors, healthcare systems & JNS: Peds \\
\hline Sean Lew & Medical College of Wisconsin & Epilepsy, cervical spine, craniocervical & JNS: Peds \\
\hline David Limbrick & Washington University in St. Louis & Chiari malformation, spine, brain tumors, hydro- & JNS: Peds \\
\hline Daniel Lu & University of California, Los Angeles & Spinal cord injury, degenerative spine, deformity & JNS: Spine \\
\hline William Mack & University of Southern California & Vascular/endovascular & JNS \\
\hline Daniel Prevedello & The Ohio State University & Skull base, neuroendoscopy, brain tumors & JNS \\
\hline Wilson Z. Ray & Washington University in St. Louis & Cervical, minimally invasive, peripheral nerve & JNS: Spine \\
\hline
\end{tabular}

small fraction of the total each year. ${ }^{2}$ We are continuously seeking the best science and the highest-quality studies in our specialty.

Naturally, we encountered many new submissions relating to the impact of COVID-19 on the practice of neurosurgery. ${ }^{3}$ In this regard, we received reports daily from around the globe, beginning in mid-March, first from China and then sequentially from other countries that were hit hardest by the virus. Most of these reports were limited case observations, many reporting on patient triage, neurosurgical preparation and technique, safety, and COVID-19-related neurological complications such as intracranial thrombosis and hemorrhage. While these reports were initially intriguing, our global readers were experiencing the same events at their own centers. Thus, what initially appeared novel in March or early April 2020 became somewhat more routine by May. This shared adaptation to the shutdown of elective neurosurgical procedures influenced our own peer-review decisions on manuscripts related to COVID-19.

At the apex of the pandemic, it became quite clear to us that the number of editorial board members for the journal was likely out of balance with the number of manuscripts received. Each member of the editorial board reviews between 100 and 175 manuscripts annually. The co-chairs of the editorial board review even more. Given the annual steady rise in manuscript submissions to the journal, which has not yet plateaued, at our recent virtual editorial board meeting on April 26, 2020, we reviewed and accepted the nominations of 14 new members for the editorial board (Table 1). In previous years, we would have typically accepted approximately 8 new editorial board members.

We were delighted to see neurosurgeons around the globe putting pen to paper during the pandemic and using their time wisely to enhance the academic mission of their programs and institutions in these most uncertain times. Being academically productive in a challenging environment is a true testament to the fortitude, resiliency, and adaptability of neurosurgeons around the world, in addition to their prodigious work ethic. It will be interesting to track and follow the increased number of papers that are being published from the period of the pandemic to determine if the sudden influx of novel ideas and applications of new technologies stimulate advances in neurosurgery to the great benefit of our patients.

https://thejns.org/doi/abs/10.3171/2020.7.JNS202691

\section{References}

1. Bauchner H, Fontanarosa PB, Golub RM. Editorial evaluation and peer review during a pandemic. How journals maintain standards. JAMA. Published online June 26, 2020. doi:10.1001/jama.2020.11764

2. Kondziolka D, Rutka JT. Editorial. A concerted effort to publish the best studies in neurosurgery. J Neurosurg. 2017;126(5):1445-1447.

3. Kondziolka D, Couldwell WT, Rutka JT. Introduction. On pandemics: the impact of COVID-19 on the practice of neurosurgery. J Neurosurg. 2020;133(1):1-2.

\section{Disclosures}

The authors report no conflict of interest.

\section{Correspondence}

James T. Rutka: james.rutka@sickkids.ca.

INCLUDE WHEN CITING

Published online July 24, 2020; DOI: 10.3171/2020.7.JNS202691. 